\title{
Influence of Fatty Acid Methyl Esters on Fuel properties of Biodiesel Produced from the Seeds Oil of Curcubita pepo
}

\author{
${ }^{* 1}$ M.A. Sokoto, ${ }^{1}$ L.G. Hassan, ${ }^{1}$ S.M. Dangoggo, ${ }^{2}$ H.G. Ahmad and ${ }^{1}$ A. Uba \\ ${ }^{1}$ Department of Pure and Applied Chemistry, Usmanu Danfodiyo University, Sokoto \\ ${ }^{2}$ Department of Crop Science, Usmanu Danfodiyo University, Sokoto
}

[Corresponding author E-Mail: abdullahiso@yahoo.com; Tel.: +234(0)7034525732]

\begin{abstract}
Oil extracted from the seeds of Curcubita pepo was transesterified using potassium aydroxide in methanol. Fatty acid methyl esters (FAME) profile of the produced diesel was analyzed using Jas chromatograph coupled with mass spectrophotometer (GC-MS). The results indicate the presence of nethyl (12E)-octadecenotate as the dominant ester with approximate percentage by composition of $82.90 \%$. Jther esters detected were methyl tetradecanoate $(0.4 \%)$, methyl eicosonoate $(2.48 \%)$, methyl docosanoat $\epsilon$ $0.97 \%)$ methyl teracosanoate $(0.47 \%)$. Some critical fuel parameters like oxidation stability, cetan uumber, iodine value and viscosity were correlated with the methyl ester composition and structura zonfiguration. It was found that the cetane number and oxidation stability of the produced biodiesel is a unction of the degree of unsaturation and long chain saturated factor. The profile of methyl esters in the siodiesel produced indicates its likelihood to be a viable fuel source for internal combustion engines.
\end{abstract}

Key words: Curcubita pepo, transesterification, methyl fatty acid esters (FAMEs), Cetane number

\section{INTRODUCTION}

Energy use is one of the most fundamental requirements for human existence. It is a critical factor for social and economic development, and a viable commodity that could improve human well being. Nigeriaôs energy sector is heavily dependent on petroleum fuels. This is more pronounced in the transportation and electricity generation subsectors. Quest for sustainable alternatives sources (to augment these source) from new and renewable energy resources is a critical factor for achieving sustainable economic development as well as an avenue for reducing the consequences of greenhouse gases emissions and global warming. Though Nigeria is a developing nation with a population of over 140 millions people and the sixth oil producing nation in the world, yet is bedeviled with insufficient energy supply. Therefore, diversification of energy sources especially by exploitation of biomass resources, which are capable of fulfilling an increase in energy supply with zero effect on food basket, is necessary. This could be a strategy to remedy the persistent insufficiency in energy supply.

In this connection, biodiesel which mainly consist of mixtures of alkyl esters remain one of the promising liquid alternative fuel supplementing the petroleum-based diesel fuel; consequent upon its similarity in terms of fuel properties (Knothe, 2008).

Various specifications that a biodiesel fuel must meet as contained in biodiesel standards, (such as American Society for Testing and Materials (ASTM) D6751 and EN 14214 in Europe) are associated with the composition and structure of the fatty esters comprising the biodiesel (Mittelbach and Remschmidt, 2004). Some of these specifications that are related to fuel quality include cetane number, kinematic viscosity, oxidative stability and cold-flow properties in form of the cloud and pour points (Knothe et al., 2005; Knothe, 2008; Knothe, 2009; Ramos et al., 2009). Other essential properties influenced by fatty ester components of biodiesel but not contained in biodiesel standards are exhaust emissions, lubricity and heat of combustion (Ramos et al., 2009). The ester moiety derived from the alcohol can influence the fuel properties of biodiesel like cetane number $(\mathrm{CN})$, viscosity, oxidation stability among others (Knothe, 2005).

The focus of the present work is to investigate the profile of fatty acid methyl esters in the biodiesel produced from C. pepo seed oil and study their influence on biodiesel fuel properties which include cetane number, viscosity, iodine value, 
heat of combustion, oxidative stability and coldflow.

\section{EXPERIMENTAL}

\section{Sampling and Sample Treatment}

Matured pumpkin seeds (plate 1), popularly known as óKabushi' in native Hausa language were obtained from ñKasuwar Daji marketô in Sokoto metropolis in March 2010. The procured seeds samples were stored in a polyethene bag under laboratory condition prior to the pretreatment stage. The sampled seeds were dehulled manually to obtain the seed kernel, which was crushed to powder using pestle and mortar in the laboratory. Oil was extracted from the powdered sample seeds manually by hot water stirring method.

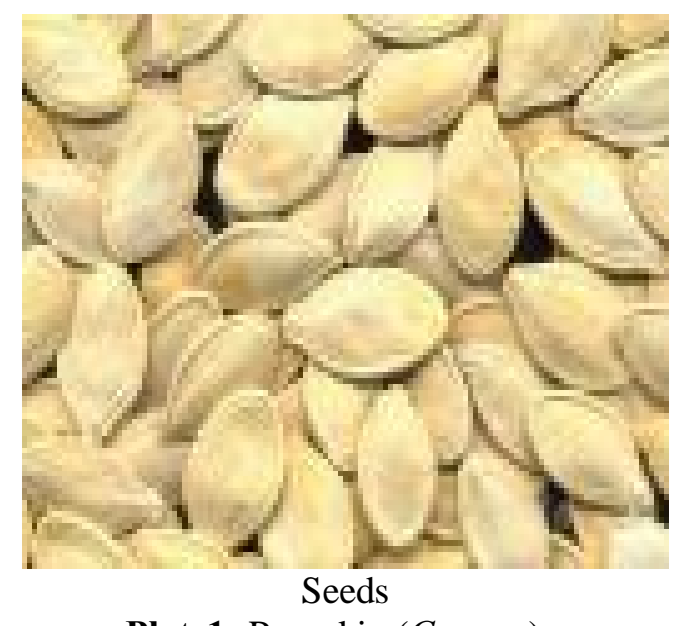

Plate1: Pumpkin (C. pepo)

\section{Transesterification}

Base-catalyzed reaction was employed for the transesterification of the extracted oil. Vegetable oils are usually associated with low free fatty acid content (Carraretto et al., 2004), therefore, the extracted oil was transesterified homogeneously, using single step batch process as described by Demirabas (2005). Briefly, $1 \mathrm{~g}$ of $\mathrm{KOH}$ in $75 \mathrm{~cm}^{3}$ of methanol, was mixed with $100 \mathrm{~g}$ of the $C$. pepo oil in a $500 \mathrm{~cm}^{3}$ round bottom flask fitted with a cork. The content was stirred on magnetic stirrer for 5 minutes. The mixture was then heated on a water bath at $60^{\circ} \mathrm{C}$ for one hour. It was transferred into separating funnel and allowed to stand overnight. Two distinct layers were observed; a thick brown layer (glycerol) at the bottom and a yellowish colour layer constituting the upper layer (biodiesel)
(Demirabas, 2005).The biodiesel layer was placed into an evaporating dish and heated over water bath at $90^{\circ} \mathrm{C}$ to remove the residual methanol. The methyl esters was then washed with $5 \mathrm{~cm}^{3}$ of $0.1 \mathrm{M}$ phosphoric acid followed one $1: 5 \mathrm{~cm}^{3}$ of water until the washed water has a $\mathrm{pH}$ of 7.0. The residual water was removed by drying the methyl ester over heated $\left(100^{\circ} \mathrm{C}\right)$ anhydrous sodium sulphate (Demirbas, 2008).

\section{GC-MS analysis}

A QP- 2010 model GC-MS machine was used for the characterizations of biodiesel. In the conduct of the analysis, 2 عl (micro liters) of the biodiesel sample was injected into the gas chromatograph with its oven temperature program between $60^{\circ} \mathrm{C}$ $280^{\circ} \mathrm{C}$ at $5^{\circ} \mathrm{C} / \mathrm{min}$ holding time. The injected sample in the gas chromatograph, separated on a column. Helium gas as a carrier gas and mass selective detector was used for the analyses. The analyses were done scan in scan mode and the components identified based on software matching with standard mass spectra. The relative peak areas of the components are assumed to be the efficient to the weight proportion of the components.

Saponification and iodine values of the biodiesel were respectively calculated from equations 1 and 2 (Mohibbe et al., 2005).

$$
\begin{aligned}
& I V=\sum \frac{\left(254 X D X A_{i}\right)}{M W_{i}} \\
& S V=\sum \frac{\left(560 X A_{i}\right)}{M W_{i}}
\end{aligned}
$$

Where $I V$, is the iodine value, $S V$ is the saponification value, $\mathrm{D}$ is the number of double bond; $\mathrm{A}_{i}$ and $\mathrm{MW}_{i}$ are the percentage composition and molecular mass of a particular ester, respectively.

Cetane number was calculated from equation 3 as reported by Mohibbe et al. (2005), while high heating value of the biodiesel was evaluated using equation 4 (Demirbas, 2008).

$$
\begin{gathered}
C N=46.3+\frac{5458}{S V}-0.225 X I v \\
H H V(M J / k g)=49.43-0.041(S v) \\
-0.015(I v)
\end{gathered}
$$


Where $\mathrm{CN}$ is the cetane number and HHV is the high heating value. Degree of unsaturation (DU) was determined based on percentages of monounsaturated and poly unsaturated FAMEs of the produced biodiesel using equation 5 (Mohibbe et al., 2005).

$$
\begin{aligned}
\mathrm{DU}= & (\text { monosaturated } \mathrm{Cn}: 1 \mathrm{wt} \%) \\
& +2(\text { Polyunsaturated } \mathrm{Cn}: 2,3 \mathrm{wt} \%)
\end{aligned}
$$

\section{RESULTS AND DISCUSSION}

The methyl ester composition in biodiesel produced from C. pepo oil shown in Table 1, indicate the presence of methyl tetradecanoate $\left(\mathrm{C}_{15} \mathrm{H}_{30} \mathrm{O}_{2}\right)$ having a percentage $0.4 \%$ by weight.

Table 1: Methyl Fatty Acids Esters of C. pepo seeds Biodiesel

\begin{tabular}{lc}
\hline Methyl esters Approximate composition (\%) \\
\hline Methyl tetradecanoate & 0.4 \\
Methyl hexadecanoate & 9.36 \\
Methyl(12E)-octadecenoate & 82.90 \\
Methyl eicosanoate & 2.48 \\
Methyl docosanoate & 0.97 \\
Methyl tetracosanoate & 0.47 \\
Other non methyl ester & 3.42 \\
\hline
\end{tabular}

Methyl hexadecanoate $\left(\mathrm{C}_{17} \mathrm{H}_{34} \mathrm{O}_{2}\right)$ and methyl (12E)-octadecenoate $\left(\mathrm{C}_{19} \mathrm{H}_{36} \mathrm{O}_{2}\right)$ were also detected. Their respective percentages by composition were 9.63 and $82.90 \%$. Other esters found in the biodiesel were methyl eicosanoate $\left(\mathrm{C}_{21} \mathrm{H}_{42} \mathrm{O}_{2}\right)$, methyl docosanoate $\left(\mathrm{C}_{23} \mathrm{H}_{46} \mathrm{O}_{2}\right)$ and methyl tetracosanoate $\left(\mathrm{C}_{25} \mathrm{H}_{50} \mathrm{O}_{2}\right)$; having respective percentages of $2.48,0.97$ and 0.47 . The profile revealed the methyl (12E)-octadecenoate $\left(\mathrm{C}_{19} \mathrm{H}_{36} \mathrm{O}_{2}\right)$ as the predominant compound in the mixture having the highest percentage of $82.90 \%$.

The fatty acid methyl ester profile is one of the key factors that determine the suitability or otherwise of any feedstock for use in biodiesel fuel production (Knothe, 2009). The results in Table 1 indicate that, the most abundant ester in the $C$. pepo diesel is monounsaturated methyl (12E) octadecenoate. It is good compound with respect to stability of the biodiesel as higher degree of unsaturation in the fatty acid methyl esters limits its suitability for use as a fuel due high polymerization tendency as result of peroxidation (Gaby and Peter, 1997). At high temperature, commonly experienced in combustion engines, the peroxidation can be accelerated and engine can quickly become gummed with polymerized fatty methyl esters (Mohibbe et al., 2005). Hence, feedstock with high percentage of polyunsaturated acid is not suitable for usage as biodiesel. Since the dominant fatty acid methyl esters methyl (12E) octadecenoate and methyl hexadecanoate are monounsaturated they might have no much affinity to oxygen that will lead to quick peroxidation. These dominant esters were similar to the major fatty acid methyl esters in $J$. curcus having percentages of 51.7 and 14.3 respectively (Andrew et al., 2009). Palm and olive oil methyl esters has been reported to be a good feedstock for biodiesel production (Andrew et al., 2009), their dominant esters are methyl (12E) octadecenoate and methyl hexadecanoate similar to those of $C$. pepo. Similarly, methyl (12E) octadecenoate and methyl hexadecanoate were the dominant esters in rape seed methyl esters with percentage composition of 77.9 and 3.86 (Bamgboye and Hansen, 2008). Likewise in Rhus succelanea Linn and Annona reticulate as reported by Martini and Shell (2008) and Harrington (1986) respectively. Hence, it could be deduce that, C. pepo FAMEs, has some of the viable characteristic of being a good material for biodiesel production.

\section{Cetane number (CN)}

Cetane number $(\mathrm{CN})$ is widely used as diesel fuel quality parameter related to the ignition delay time and combustion quality. The higher the cetane number is, the better it is in ignition property (Meher et al., 2006), and the greater quality of methyl ester to be used as a diesel fuel. An adequate cetane number is required for good engine performance. High cetane numbers help ensure good cold start properties and minimize the formation of white smoke. Cetane number is measured by correlating the fuel value against the reference fuel most commonly the n-cetane. This study takes an approach to estimate the cetane number of biodiesel, according to equation (3).

The calculated cetane number is shown in Table 2 . The longer the fatty acid carbon chains and the more saturated the molecules, the higher the cetane number (Knothe et al., 1998; Dermibas, 
2005; Bajpai and Tyagi, 2006). Cetane number decreases with increasing number of carbon atoms and increase in unsaturation. Considering the carbon chain in the dominating ester and its low degree of unsaturation, signifies an expectedly high cetane number (60.01) in diesel prepared from the C. pepo seeds oil. According to UNE-EN 14214 (2003) specification, biodiesel should have minimum cetane number of 51, while ASTM D6751- 02 ascribes 47 as the minimum cetane for biodiesel. Based upon these standards, biodiesel produce from $C$. pepo possess good ignition quality, as its cetane number exceed the minimum standard value. Low cetane number have been associated with more highly unsaturated components such as the esters of linoleic (C18:2) and linolenic (C18:3) acids (Knothe et al., 2003), both of which were not detected in C. pepo biodiesel. According to Knothe (2003) and Van Gerpen (1996) high cetane numbers were observed for methyl palmitate (C16:0) and stearate (C18:0) while methyl lenolenate has a very low $\mathrm{CN}$, this also conform to the results observed in the present analyses. The cetane values obtained in the present studies agreed with those of soybean oils that ranged from 45 to 60 and the of rapeseed biofuel that ranged 48-61.2 (Bamgboye and Hansen, 2008).

Table 2: Physicochemical Properties of C. pepo Seeds Biodiesel

\begin{tabular}{ll}
\hline Parameter & Values \\
\hline Saponification value $(\mathrm{mgKOH})$ & 183.66 \\
Iodine value $\left(\mathrm{mgI}_{2} / 100 \mathrm{~g}\right)$ & 71.14 \\
Cetane number & 60.01 \\
High heating value $(\mathrm{MJ} / \mathrm{Kg})$ & 40.84 \\
Saturated FAME $(\%)$ & 13.68 \\
Monounsaturated FAME $(\%)$ & 82.90 \\
Polyunsaturated FAME $(\%)$ & 0.00 \\
Degree of Unsaturation & 82.90 \\
\hline
\end{tabular}

The kinematic viscosity (3) is the resistance to flow of a fluid under gravity. Fuel viscosity has a significant impact on the operation of engine fuel injection and atomization systems and is known to affect engine wear and the rate of injector fouling. Viscosity of biodiesel depends on the structural composition of the parent or virgin oil used in biodiesel production. Viscosity increases with the number of $\mathrm{CH}_{2}$ moieties in the fatty ester chain and decreases with an increasing unsaturation (Knothe, 2008 and Razon, 2009). This implies that presence of multiple bonds impart low viscosity to biodiesel. Therefore, the viscosity of the produced biodiesel could be high due to the level of unsaturation in the predominant ester components.

\section{Iodine value}

Iodine value measures the total unsaturation within a mixture of fatty acids. It is the amount of iodine required to iodize all the double bonds in the biodiesel. It is expressed in grams of iodine per $100 \mathrm{~g}$. Iodine value is limited to $120 \mathrm{~g} \mathrm{I}_{2} / 100 \mathrm{~g}$ in the European biodiesel standard (UNE-EN $14214,2003)$. The limit of $120 \mathrm{~g} \mathrm{I} / 2100 \mathrm{~g}$ specified by the European biodiesel standard excludes several promising oil sources (Mittelbach and Remschmidt, 2004) due to high proportion of unsaturated fatty acids in most vegetable oils. Biodiesel produced from seeds oil of $C$. pepo has iodine value within the EN 14214 specification thus has a moderate degree of unsaturation. This also re-affirmed it suitability in biodiesel production.

Stability of fatty compounds is influenced by factors such as presence of air, heat, traces of metal, peroxides, light, or structural features of the compounds themselves, mainly the presence of double bonds (Bajpai and Tyagi, 2006). The oxidation stability decreased with the increase of polyunsaturated fatty acid methyl esters content (Knothe, 2005; McCormick et al., 2007; Park et al., 2008). Autoxidation of unsaturated fatty compounds proceeds at different rates depending on the number and position of double bonds. The bis-allylic positions in common polyunsaturated fatty acids such as linoleic acid (one bis-allylic position at $\mathrm{C}-11$ ) and linolenic acid (two bisallylic positions at $\mathrm{C}-11$ and $\mathrm{C}-14$ ) are more susceptible to autoxidation than allylic positions. Relative rates of oxidation reported by Knothe, 2005; Knothe et al. (2005) are 1 for methyl oleate, 41 for methyl linoleate and 98 for methyl linolenate. Therefore, vegetable oils rich in linoleic and linolenic acids, tend to impart poor oxidation stability to fuels. The results in Table 2 infer that the produced biodiesel will be stable owing to the absence of polyunsaturatred fatty acids. 
The heat of combustion is important parameter for estimating fuel consumption. The greater the heat of combustion, the lower the fuel consumption (Knothe et al., 2008). The heat of combustion or heating value is not specified in the biodiesel standards ASTM D6751 and EN14214. However, a European standard for using biodiesel as heating oil, EN 14213, specifies a minimum heating value of $35 \mathrm{MJ} / \mathrm{kg}$. The heat of combustion increases with an increasing chain length and decreases with an increasing unsaturation. The diesel produced from $C$. pepo exceeds the minimum value for heating oil. This portrayed it usefulness as petrol diesel supplement.

\section{CONCLUSION}

There are specifications that allow variety of feedstock to be processed and used as biodiesel. The specifications prescribe the amount of acceptable variability in the finished product. This variability is a compromise between maximizing the amount of fuel available for use and minimizing cost, while providing a minimum satisfactory level of engine performance. Since biodiesel is used mainly as a fuel, some of the properties of finished biodiesel depend heavily on the feedstock. These properties can include cetane number, cold flow and stability. The results obtained revealed the presence of methyl oleate as the dominant compound in the biodiesel from $C$. pepo seeds oil. Polyunsaturated (C: 3) methyl esters were not detected in the sample. Thus extent of instability is minimal. Cetane number of the produced biodiesel is within the ASTM specification. The heating values correspond to those of other biodiesel in market. Hence biodiesel from C. pepo seed oil is recommended for use as a diesel fuel.

\section{REFERENCES}

Andrew, J. K., Wei, H., Jesus, A. C., Mark, F., Danieles, R., and Lan, A. G. (2009): Potential of Jatropha curcus as a source of renewable oil and animal feed. J. Exper. Bot. 60(10): 2897- 2905.

Bajpai, D., and Tyagi, V.K. (2006). Biodiesel: Source, Production, Composition, Properties and its Benefits. J. Oleo Sci. 55: $487 i ̈ 502$.

Bamgboye, A.I. and Hansen, A.C. (2008): Prediction of Cetane number of Biodiesel
Fuel from the fatty acid methyl ester composition. Int. J. Agrophy. 22: 21-29.

Carraretto, C., Macor, A., Mirandola, A., Stoppato, A. and Tonon, S. (2004). Biodiesel as Alternative Fuel: Experimental Analysis and Energetic Evaluations. J. Ener. 29: 21952211.

Demirabas, A. (2005). Biodiesel Production from Vegetable Oils via Catalytic and non-Catalytic Supercritical Methanol Transesterification Methods. J. Progress Ener. Combust. Sci. 31: 466-487.

Demirabas, A. (2008). Biofuel sources, Biofuel Policy, Biofuel Economy and Global Biofuel Projection. J. Ener. Conver. Manag. 49: 2106 ï 2116.

Gaby, W. and Peter, S.L. (1997). Boiling point Properties and thermal Decomposition of Vegetable Oils Methyl esters with regard to their fuel stability. J. Agric Food Chem. 45: 4748- 4752

Gopinath, A. Sukumar, P. and Nagarajan, G (2010). Effect of biodiesel structural configuration on its ignition quality. Int. J. Ener. Environ. 1(2): 395-306.

Graboski, M.S. and Mccormick, R.C. (1998). Combustion of fats and vegetable oil derived fuel in diesel engine. Progress Ener. Combust. Sci. 24:125 - 64

Harrington, K.J. (1986). Chemical and physical properties of vegetable Oil Esters and their effect on Diesel Fuel performance. Biomass 9: 1-17.

Knothe, G., (2003). Structure indices in FA chemistry. How relevant is the iodine value? J. Am. Oil Chem. Soc. 9: 847 ï 853.

Knothe, G. (2005). Dependence of Biodiesel Fuel Properties on the Structure of Fatty Acid Alkyl Esters. Fuel Process Technol. 86: 1059 $-1070$.

Knothe, G. (2008). ñDesignerò Biodiesel: Optimizing Fatty Ester Composition to Improve Fuel Properties. Ener. Fuels 22: 1358-1364.

Knothe, G. (2009). Improving Biodiesel Fuel properties by modifying fatty Esters composition. J. Ener. Environ. Sci. 10: 10391054

Knothe, G., Bagby, M.O., and Ryan III, T.W., (1998). Precombustion of Fatty Acids and Esters of Biodiesel. A possible Explanation 
for differing cetane numbers. J. Am. Oil Chem. Soc. 75: 1007ï 1013

Knothe, G., Gerpen, J.V. and Krahl, J. (2005). The Biodiesel Handbook. AOCS Press,Champaign, Illinois.

Knothe, G., Matheaus, A.C., Ryan III, T.W., (2003). Cetane Numbers of Branched and Straight Chain Fatty Esters Determined in an Ignition Quality Tester. Fuel 82: 971 ï 975.

Martini N. and Shell, J.S (2008): Plants Oils as Fuels- Present State of Science and Future Development. Springer, Berlin pp. 276.

McCormick, R.L., Ratcliff, M., Moens, L., Lawrence, R., (2007): Several Factors Affecting the Stability of Biodiesel in Standard Accelerated Tests. Fuel Process. Technol. 88: 651 ï 657.

Meher, L.C., Vidya Sagar, D. and Naik, S.N. (2006). Technical Aspects of Biodiesel Production by Transesterificationï A Review. Renew. Sust. Energ. Rev. 10: 248-268.

Mittelbach, M. and Remschmidt, C. (2004). Biodiesel the Comprehensive Hand Book. Boersedruck Ges. MBH., Vienna.

Mohibbe, A., Amtul, W. and Nahar, N.M. (2005). Prospect and Potential of Fatty Acid Methyl
Esters of some Non-traditional Seeds Oils for use as Biodiesel in India. Biomass Bioener. 29: 293-302

Park, J.-Y., Kim, D.-K., Lee, J.-P., Park, S.-C., Kim, Y.-J., Lee, J.-S. (2008). Blending effects of biodiesels on oxidation stability and low temperature flow properties. Biores. Technol. 99: 1196 ï 1203.

Ramos, M.J., Carmen, M.F, Abraham, C., Lourdes, R. and Angel, P. (2009). Influence of Fatty Acid Composition of Raw Materials on Biodiesel properties. Biores. Technol. 100: 261-268.

Razon, L.F. (2009) Alternative Crops for Biodiesel feedstock. CAB Reviews: Perspective Agric., Centenary Sci., Nutr. Nat. Res. 4(56): 1-15.

UNE-EN 14214 (2003). Automotive fuels. Fatty acid methyl esters (FAME) for diesel engines. Requirements and test methods.

Van Gerpen, J.H. (1996). Cetane Number Testing of Biodiesel. Liquid Fuels and Industrial Products From Renewable Resources. Proceedings of the Third Liquid Fuel Conference, 15ï 17 September, Nashville, Tennessee. 